\title{
Should Premarital Screening for Blood Disorders be an Obligatory Measure in Oman?
}

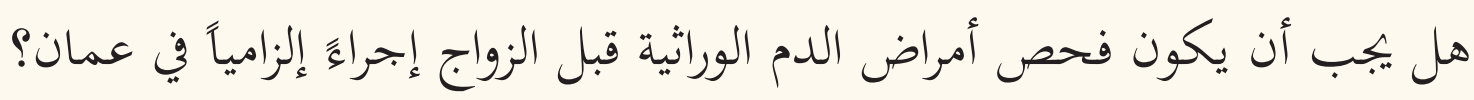

$$
\text { أمل أحمد البلوشي و بدور الهنائي }
$$

\begin{abstract}
Due to the high rate of consanguineous marriages in Oman, there is a correspondingly high prevalence of hereditary blood disorders, particularly sickle cell disease and $\beta$-thalassaemia. This article proposes the possibility of implementing mandatory premarital carrier screening for blood disorders in Oman, while giving due consideration to potential social and cultural obstacles. Although the implementation of such legislation would require collaboration between different sectors and may negatively affect the autonomy of certain individuals, mandatory premarital screening would help to alleviate the burden of hereditary blood disorders on the national healthcare system, as well as reduce avoidable suffering among carriers and their families.
\end{abstract}

Keywords: Consanguinity; Premarital Examinations; Genetic Carrier Screening; Mandatory Screening; Sickle Cell Trait; beta-Thalassemia; Oman.

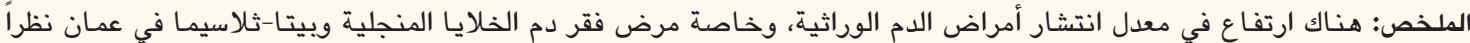

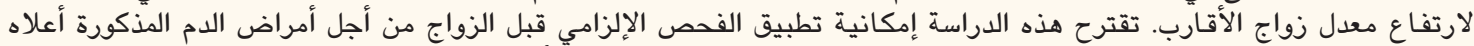

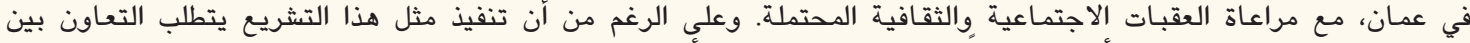

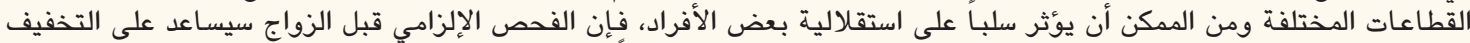

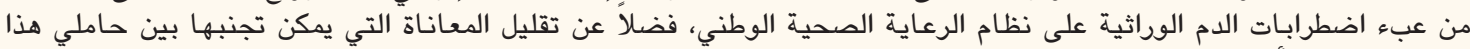

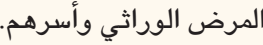

$$
\begin{aligned}
& \text { الكلمات المفتاحية؛ قرابة؛ فحص ما قبل الزواج؛ الفحص الجيني؛ الفحص الإلزامي؛ صفة نقص الدم المنجلي؛ بيتا-ثلاسيميا؛ عمان. }
\end{aligned}
$$

A S WITH MANY ARAB COUNTRIES, CONSANGuineous marriages are fairly common in Oman, accounting for $58 \%$ of all marriages. ${ }^{1,2}$ Of these consanguineous marriages, $75 \%$ are firstcousin marriages. ${ }^{3}$ Unfortunately, such unions can result in offspring with hereditary blood disorders, such as sickle cell disease (SCD) and $\beta$-thalassaemia. ${ }^{4}$ As healthcare services in Oman are free for the local population, hereditary blood disorders present a significant economic burden on the healthcare system. There is an urgent need to prioritise health services and concentrate on preventative cost-effective measures. To this end, hereditary blood disorders might be avoided if a couple is made aware of their carrier status prior to marriage using a simple premarital screening test. This article discusses the possibility of reducing the burden of hereditary blood disorders like SCD and $\beta$-thalassaemia by implementing mandatory premarital screening. In addition, the prospect of applying disincentives to atrisk couples who wish to get married is considered from an ethical standpoint.

\section{The Burden of Hereditary Diseases in Oman}

The most common hereditary blood disorders in Oman are SCD, $\beta$-thalassaemia and glucose-6-phosphate dehydrogenase (G6PD) deficiency; such diseases constitute a significant source of morbidity in addition to consuming valuable national health resources. ${ }^{1,5}$ In 2003, the Genetic Blood Disorders Survey found that approximately $6 \%$ and $2 \%$ of Omani children under five years old carried the sickle cell and $\beta$-thalassaemia genes, respectively; moreover, the prevalence of SCD was $0.2 \%$ and homozygous $\beta$-thalassaemia was $0.07 \%{ }^{2} \mathrm{~A}$ retrospective study at a tertiary hospital in Oman showed the prevalence of the sickle cell trait and SCD to be $7.5 \%$ and $0.46 \%$, respectively. ${ }^{6}$

Patients with hereditary blood disorders often experience higher rates of absenteeism and reduced academic performance due to frequent hospitalisation and follow-up appointments. ${ }^{7}$ The effects of such disorders are not only multi-systemic on the part of the individual patient, but may also affect the psychosocial 
well-being of the entire family, leading to stress and anxiety as well as a disruption of the normal family dynamic. $^{8}$ For example, healthy children may feel neglected by their parents as affected siblings receive greater care and attention or ill adults may not be able to fully fulfil their role as a caregiver or financial provider due to disease-related morbidity.

\section{Existing Premarital Screening Measures in Oman}

A premarital carrier screening service has been in place in Oman since 1999 and is available on an optional free-of-charge basis at all governmental healthcare institutions; the service includes a blood test involving carrier testing for sickle cell, $\beta$-thalassaemia and G6PD deficiency for those planning to get married. ${ }^{9,10}$ Subsequently, a counselling session is provided during which the couple receives the results of the blood test and are informed about the risk and consequences of having affected children if they are both carriers. ${ }^{10}$ They are also provided with information about possible solutions to avoid passing on the trait to their offspring, such as in vitro fertilisation combined with preimplantation genetic diagnosis. Any family history of common genetic disorders is also collected and individuals are offered additional testing, as required. ${ }^{10}$ The provision of adequate health information precedes the testing, including information regarding the diseases for which the couple will be tested, the chances that they might carry other diseases for which they will not be tested and the implications of positive or negative test results.

\section{AWARENESS AND UTILISATION OF EXISTING SERVICES}

According to a survey by Al-Farsi et al. conducted on a section of the Omani population, $89.3 \%$ of adults were aware of the availability of premarital carrier screening in Oman; however, 30.5\% were opposed to actually taking the test themselves, regardless of whether they were married or single. ${ }^{10}$ Reasons for this reluctance might be related to fears that positive carrier results could lead to the cancellation of the marriage, with various social, cultural, psychological and financial implications. As such screening in Oman is advertised on a premarital basis, people rarely undertake them before a marriage proposal. Following the proposal, excitement about the prospect of getting married may outweigh fear of the consequences of a positive carrier test result and couples may therefore neglect to take the test and decide to proceed with the wedding regardless.
A study from Saudi Arabia found that knowledge about premarital testing was associated with higher educational and income levels; thus, there is a need to increase awareness of the availability and importance of premarital screening among members of the general public who may be of lower socioeconomic status or less educated. ${ }^{11}$ Al-Farsi et al. also suggested unifying counselling and educational efforts in order to develop protocols to standardise clinical practice at primary healthcare centres and encourage knowledge and awareness of premarital screening among Omani patients. ${ }^{10}$ This recommendation might help to increase the effectiveness of the current premarital screening programme. Because they have experienced the disease themselves, SCD or $\beta$-thalassaemia patients are often more motivated than asymptomatic carriers to ask their potential partners to undergo premarital testing as they do not wish to see their children suffer in the same way. ${ }^{12,13}$ However, the aim of premarital screening is to screen all individuals planning to get married in order to identify asymptomatic carriers who may produce a symptomatic child. Making premarital screening compulsory is one way to achieve this goal.

\section{Mandating Premarital Carrier Screening}

\section{SOCIAL AND HEALTH-RELATED BENEFITS}

The objective of a successful mandatory premarital screening programme is to reduce the number of individuals with hereditary disorders by minimising marriages between carriers and increasing the use of reproductive technologies that eliminate the risk of having a sick child. In Turkey, a mandatory premarital screening programme resulted in the cancellation of $53 \%$ of at-risk marriages and an $80 \%$ reduction in at-risk births. ${ }^{14}$ Similarly, mandatory premarital screening in Bahrain led to a $58 \%$ cancellation rate of atrisk marriages. ${ }^{14}$ In Saudi Arabia, the prevalence of $\beta$-thalassaemia dropped from $32.9 \%$ to $9.0 \%$ following the implementation of mandatory premarital screening; in addition, there was a $60 \%$ reduction in the number of at-risk couples and a $51.9 \%$ cancellation rate of at-risk marriages. ${ }^{15}$

There are many potential advantages to making premarital screening an obligatory measure for Omani couples planning to get married. Social benefits of mandatory premarital screening include the possibility of increased family bonding, decreased absenteeism from school or work and a better quality of life (QOL), although these factors are often difficult to assess quan- 
titatively. Mandatory premarital screening would also prevent the inconvenience or potential social awkwardness of individuals having to ask their partner to get tested. Couples who are interested in marrying each other would be able to immediately determine their carrier status and thus make informed decisions regarding the potential union. Al-Farsi et al. reported that $49.5 \%$ of Omani adults in their study agreed that premarital testing should be compulsory. ${ }^{10}$ In another study, $53 \%$ of Omani university students preferred mandated premarital screening and $36 \%$ were of the opinion that high-risk marriages should be prevented by law. ${ }^{9}$ A study conducted in Saudi Arabia indicated that $60.3 \%$ of participants encouraged obligatory premarital screening. ${ }^{16}$

\section{ECONOMIC BENEFITS}

On average, the annual cost of haemoglobinopathy management is estimated to be $\$ 4,425-7,000$ USD per patient. ${ }^{17}$ Inclusive of the financial costs associated with new cases arising each year, the overall economic burden of these disorders on the national healthcare system can reach $\$ 1.36$ million USD. ${ }^{18}$ On the other hand, the cost of carrier screening, including personnel costs, is \$20-30 USD per test; testing the entire Omani population aged 15-19 years old over a five-year period would therefore amount to $\$ 800,000$ USD annually. ${ }^{17,19}$ This annual cost is approximately equivalent to that currently being spent on treating haemoglobinopathy patients; however, this figure does not represent other financial costs related to the psychological and social aspects of hereditary diseases, such as QOL.

\section{LEGISLATIVE AND PRACTICAL BARRIERS}

Nevertheless, the implementation of a mandatory screening programme may also have several disadvantages. One difficulty would lie in regulating the entire marriage and screening process-which would require the involvement of several governmental bodies, including the Ministries of Health, Education, Justice, Legal Affairs, Religious Affairs and Civil Services as well as the National Youth Committee-in a way that is comprehensive and yet still convenient for the public. Second, it might be argued that mandatory screening restricts personal autonomy by forcing individuals to get tested regardless of their personal inclinations and may violate confidentiality by exposing private carrier status information to possible future partners. However, it is important to determine whether an individual's right to privacy eclipses another's right to know their partner's carrier status and the preventable risks to which their offspring may be exposed. Moreover, every individual also has the right to enjoy their share of public health services; these are potentially reduced by the management of preventable diseases consuming valuable healthrelated resources. If the incidence of such diseases could be reduced, members of the public would be more able to benefit from other health services such as dental care, which is not easily available due to long waiting lists. Therefore, implementing such a measure can be considered generally beneficial to the Omani community at large.

Another potential obstacle that might arise with a mandatory screening policy is the decision by some at-risk couples to go ahead with the marriage despite the knowledge that each pregnancy would have a 50\% chance of producing an affected child. Of those at-risk couples who underwent premarital testing in Saudi Arabia, Ibrahim et al. found that $40 \%$ subsequently cancelled their marriage plans. ${ }^{11}$ In contrast, Al-Farsi et al. found that $14.8 \%$ of surveyed Omanis would marry even if they found out their future spouse was a carrier; moreover, $37.5 \%$ stated that they would not be willing to change their decision to marry based on premarital screening results. ${ }^{10}$ However, this issue could potentially be solved by increasing awareness of the importance of premarital screening and the consequences of passing on hereditary blood disorders. Other factors affecting this issue might be an incomplete understanding of the potential risks of consanguinity due to inadequate counselling provided by healthcare workers. ${ }^{14,15}$ Healthcare workers therefore need to have adequate time and training devoted to enhancing their genetic counselling skills.

A combination of two models could be used to change an individual's behaviour with regards to the acceptance of premarital screening. The cognitive model is concerned with influencing conscious thoughts, while the contextual model aims to make the intended behaviour more favourable under the assumption that people are affected by various factors in their environment and that their choices are therefore not always rational. ${ }^{20}$ Instead of focusing efforts solely on awareness, as per the cognitive model, a contextual change could involve adjusting the time point at which the test is performed, particularly as this may play an important role in the outcome. . $^{14,21}$

Currently, those who undergo premarital screening in Oman are usually already engaged to be married and may therefore choose to ignore unfavourable screening results. ${ }^{10,21,22}$ Mandatory screening should be carried out well before the individual is likely to get engaged, preferably during high school or university. 10,15,23 Moreover, providing premarital screening to individuals in late adolescence or early adulthood would allow for better comprehension of the implications of the 
results and might allow an individual to direct their search for a partner instead of, for example, offering testing alongside childhood vaccinations. Even though the latter option would allow for greater coverage of the local population, neonatal screening for haemoglobinopathies would have limited success due to the likelihood of false-positive results arising from the presence of fetal haemoglobin in infants under six months of age. ${ }^{24}$ In the researchers' opinion, mandatory premarital screening should be performed at the age of 16 years at primary healthcare institutions where optional screening is already being provided. Students in the $10^{\text {th }}$ grade can undertake mandatory premarital screening as part of their general health check-up. For those who do not undergo screening at this time, an alert reminding the physician to perform the test should appear on the patient's electronic health record whenever they subsequently seek medical care.

\section{CULTURAL, RELIGIOUS AND SOCIAL BARRIERS}

Religious beliefs, cultural attitudes and education are important determinants of the success of a premarital screening programme. ${ }^{14,25}$ Current cultural norms in some parts of the country are encouraging as to the acceptance of premarital screening, while many individuals in other regions still view screening as a possible obstacle to a fruitful marriage.

Reproduction in Oman is socially and religiously acceptable only within the context of marriage. However, it is important to mention that the implementation of a mandatory premarital screening programme is not intended to prevent consanguineous marriages, as carriers can still marry non-carrier partners within their family circle; rather, the aim is to give people with abnormal genes the chance to make an informed decision regarding their reproductive health and the health of their offspring. ${ }^{26}$ Nevertheless, the implementation of such a policy might encounter resistance from the public as it might be interpreted as a method of forcing them to marry outside of their own family. Despite the wide range of ethnic diversity in Oman, there are various cultural barriers to banning consanguineous marriages. Many Omanis view consanguineous marriage to be economically beneficial since it helps to retain a family's wealth or property. ${ }^{3,27}$ Moreover, it is often perceived as an ideal method of strengthening relationships within a tribe. ${ }^{27,28}$ In addition, wedding arrangements tend to be less complicated and the financial burden is reduced if the couple is from the same family. ${ }^{27,29}$ Such marriages are also deemed to increase the chances of suitability between couples and decrease the likelihood of divorce. ${ }^{27}$ Therefore, prior to its implementation, members of the Omani public should be assured that a mandatory premarital screening policy is not aimed at preventing consanguineous marriages, but rather at promoting good health.

In many Islamic societies, including Oman, the termination of a pregnancy is not accepted as it is believed to be a form of murder. ${ }^{27}$ At-risk couples who choose to get married regardless of the possibility of having an affected child would therefore not have the option to selectively terminate affected fetuses. However, such couples could choose to refrain from having biological children and adopt instead, or undergo preimplantation genetic diagnosis prior to in vitro fertilisation. ${ }^{4}$ Preimplantation genetic diagnosis is welcomed in Islamic societies as a method of preventing hereditary diseases as it is not perceived as terminating a living being. ${ }^{27}$ However, such services are not offered at governmental institutions in Oman; couples seeking this service would therefore have to visit a private health institution either locally or abroad.

The obligatory nature of premarital screening might also result in social stigma, with the families of carriers potentially ostracised or unable to find a non-carrier partner for their child within their community., ${ }^{1,15}$ However, this should not be a major obstacle provided that effective awareness and educational programmes are promoted to address such fears. ${ }^{30}$ Emphasis should be placed on the prevalence of these diseases and the duty of members of society to prevent suffering in the next generation of children. In addition, the public needs to be educated regarding the precise medical implications of carrier status, as some individuals might associate being a carrier as equivalent to having the disease. Moreover, some individuals may interpret the Islamic belief in predestination to signify acceptance of having an ill child. ${ }^{14}$ However, it is important to note that Islamic beliefs also encourage taking the causes of ill health into consideration and making healthy choices accordingly. ${ }^{14}$

\section{Disincentives for At-Risk Couples}

Patients need to be involved within the healthcare process and must therefore be made responsible for their choices. From a liberal egalitarian perspective, individuals should have access to equal health resources for diseases that are outside of their control, but not for those arising from their own choices. ${ }^{31}$ This argument would hold the parents of offspring with SCD or $\beta$-thalassaemia responsible for their child's illness due to their having neglected premarital screening or having failed to act on the test results of such screening. Policy-makers could therefore apply financial disincentives to the parents of patients with hereditary blood diseases. These could be 
in the form of paying all or part of the cost of treatment and management of an affected child or instituting fines for all at-risk married couples, even if they do not give birth to an affected child. Nevertheless, neither carriers nor those affected by hereditary disorders are responsible for their genetic material. Disincentives may therefore unequally discriminate against such individuals and it would not be fair to penalise or deny patients necessary healthcare because of a decision made by someone else (i.e. their parents). One can argue that such patients are already penalised enough by virtue of their ill health and therefore do not need an additional penalty in the form of disincentives.

On the other hand, financial deterrents will spare the government from having to fund the treatment of certain hereditary disorders, thereby allowing for the more efficient allocation of already limited resources. Moreover, such disincentives will not affect an individual's liberty as the decision to marry remains up to the couple; should they nevertheless opt to take the risk and marry, knowing that they are both carriers, they will still be able to do so at an additional cost. However, one might argue that a couple's autonomy is nevertheless restricted by such a measure. Moreover, individuals with low incomes may not be able to go ahead with a marriage in view of the potential financial deterrents. Therefore, this measure may unfairly disadvantage those with lower incomes.

The implementation of any deterrent or disincentive measures should be delayed until after the mandatory premarital screening programme has been put into effect, as it may subsequently be found that such measures are not necessary. However, if unavoidable, policy-makers should take certain factors into account when deciding to apply disincentive measures, possibly by excluding or reducing the fines or co-payments of low-income individuals. One way to make this policy more equitable would be to base the amount on a predetermined proportion of the household's income. In general, disincentives may be deemed necessary by experts on the behalf of the entire community, in that the ideal wellbeing of a few individuals is a justifiable sacrifice in view of the best interests of the public.

\section{Conclusion}

Mandating premarital screening could alleviate the unnecessary burden of hereditary blood disorders in Oman. Compulsory premarital screening is recommended for all Omani adolescents at approximately 16 years old so as to cover the entire target population at an early age; this could also help avoid the potential inconvenience associated with learning of positive screening results after becoming engaged. However, in order to implement such legislation, multilevel collaboration is needed among various institutions in Oman. In addition, various awareness and educational programmes may be necessary to ensure compliance and understanding of the goals of the programme within the Omani population.

\section{ACKNOWLEDGEMENTS}

The authors would like to thank the editors and anonymous reviewers for their valuable comments on this article.

\section{References}

1. World Health Organization Regional Office for the Eastern Mediterranean. Community control of genetic and congenital disorders. From: apps.who.int/iris/handle/10665/119571 Accessed: Dec 2017.

2. Al-Riyami A, Ebrahim GJ. Genetic blood disorders survey in the Sultanate of Oman. J Trop Pediatr 2003; 49:11-20.

3. Islam MM. The practice of consanguineous marriage in Oman: Prevalence, trends and determinants. J Biosoc Sci 2012; 44:571-94. doi: 10.1017/S0021932012000016.

4. Howard J, Telfer P. Sickle Cell Disease in Clinical Practice. London, UK: Springer, 2015. Pp. 18-28. doi: 10.1007/978-1-44 71-2473-3

5. Aneke JC, Okocha CE. Sickle cell disease genetic counseling and testing: A review. Arch Med Health Sci 2016; 4:50-7. doi: 10.4103/2321-4848.183342.

6. Adly G, Rajappa A. Haemoglobinopathies encountered at Khoula Hospital, Oman: A retrospective study. Sultan Qaboos Univ Med J 2008; 8:59-62.

7. Al-Saqladi AM. The impact of sickle cell disease severity on school performance in affected Yemeni children. J Appl Hematol 2016; 7:124-30. doi: 10.4103/1658-5127.198506.

8. Rees DC, Williams TN, Gladwin MT. Sickle-cell disease. Lancet 2010; 376:2018-31. doi: 10.1016/S0140-6736(10)61029-X.

9. Al Kindi R, Al Rujaibi S, Al Kendi M. Knowledge and attitude of university students towards premarital screening program. Oman Med J 2012; 27:291-6. doi: 10.5001/omj.2012.72.

10. Al-Farsi OA, Al-Farsi YM, Gupta I, Ouhtit A, Al-Farsi KS, Al-Adawi S. A study on knowledge, attitude, and practice towards premarital carrier screening among adults attending primary healthcare centers in a region in Oman. BMC Public Health 2014; 14:380. doi: 10.1186/1471-2458-14-380.

11. Ibrahim NK, Bashawri J, Al Bar H, Al Ahmadi J, Al Bar A, Qadi M, et al. Premarital screening and genetic counseling program: Knowledge, attitude, and satisfaction of attendees of governmental outpatient clinics in Jeddah. J Infect Public Health 2013; 6:41-54. doi: 10.1016/j.jiph.2012.05.001.

12. Ross PT. Motivations of women with sickle cell disease for asking their partners to undergo genetic testing. Soc Sci Med 2015; 139:36-43. doi: 10.1016/j.socscimed.2015.06.029.

13. Gallo AM, Wilkie D, Suarez M, Labotka R, Molokie R, Thompson A, et al. Reproductive decisions in people with sickle cell disease or sickle cell trait. West J Nurs Res 2010; 32:1073-90. doi: 10.1177/ 0193945910371482.

14. Saffi M, Howard N. Exploring the effectiveness of mandatory premarital screening and genetic counselling programmes for $\beta$-thalassaemia in the Middle East: A scoping review. Public Health Genomics 2015; 18:193-203. doi: 10.1159/000430837. 
15. Alhamdan NA, Almazrou YY, Alswaidi FM, Choudhry AJ. Premarital screening for thalassemia and sickle cell disease in Saudi Arabia. Genet Med 2007; 9:372-7. doi: 10.1097/GIM.0 b013e318065a9e8.

16. El-Hazmi MA. Pre-marital examination as a method of prevention from blood genetic disorders: Community views. Saudi Med J 2006; 27:1291-5

17. World Health Organization. Guidelines for the control of haemoglobin disorders. From: http://apps.who.int/iris/handle/10665/ 66665 Accessed: Dec 2017.

18. Alkindi S, Al Zadjali S, Al Madhani A, Daar S, Al Haddabi H, $\mathrm{Al}$ Abri Q, et al. Forecasting hemoglobinopathy burden through neonatal screening in Omani neonates. Hemoglobin 2010; 34:135-44. doi: 10.3109/03630261003677213.

19. National Centre for Statistics and Information. Data portal: Population. From: http://data.gov.om/OMPOP2016/population? age-group=1000410 Accessed: Dec 2017 .

20. Institute for Government Cabinet Office. MINDSPACE: Influencing behaviour through public policy. From: www.institutefor government.org.uk/sites/default/files/publications/MINDSP ACE-Practical-guide-final-Web_1.pdf Accessed: Dec 2017.

21. Al-Aama JY. Attitudes towards mandatory national premarital screening for hereditary hemolytic disorders. Health Policy 2010; 97:32-7. doi: 10.1016/j.healthpol.2010.02.009.

22. Alswaidi FM, Memish ZA, O’Brien SJ, Al-Hamdan NA, Al-Enzy FM, Alhayani OA, et al. At-risk marriages after compulsory premarital testing and counseling for $\beta$-thalassemia and sickle cell disease in Saudi Arabia, 2005-2006. J Genet Couns 2012; 21:243-55. doi: 10.1007/s10897-011-9395-4.
23. Memish ZA, Saeedi MY. Six-year outcome of the national premarital screening and genetic counseling program for sickle cell disease and $\beta$-thalassemia in Saudi Arabia. Ann Saudi Med 2011; 31:229-35. doi: 10.4103/0256-4947.81527.

24. Giordano P. Newborn screening for haemoglobinopathies. In: Old J, Ed. Prevention of Thalassaemias and Other Haemoglobin Disorders, 2nd ed. Nicosia, Cyprus: Thalassaemia International Federation, 2013

25. Hashemizadeh H, Noori R. Premarital screening of beta thalassemia minor in north-east of Iran. Iran J Ped Hematol Oncol 2012; 3:210-15.

26. Modell B, Kuliev A. The history of community genetics: The contribution of the haemoglobin disorders. Community Genet 1998; 1:3-11. doi: 10.1159/000016129.

27. Hamamy H, Bittles AH. Genetic clinics in Arab communities: Meeting individual, family and community needs. Public Health Genomics 2009; 12:30-40. doi: 10.1159/000153428.

28. Kilshaw S, Al Raisi T, Alshaban F. Arranging marriage, negotiating risk: Genetics and society in Qatar. Anthropol Med 2015; 22:98-113. doi: 10.1080/13648470.2014.976542.

29. Bittles AH, Mason WM, Greene J, Rao NA. Reproductive behavior and health in consanguineous marriages. Science 1991; 252:789-94. doi: 10.1126/science.2028254

30. Al-Gazali L, Hamamy H, Al-Arrayad S. Genetic disorders in the Arab world. BMJ 2006; 333:831-4. doi: 10.1136/bmj.38 982.704931.AE.

31. Cappelen AW, Norheim OF. Responsibility, fairness and rationing in health care. Health Policy 2006; 76:312-19. doi: 10.1016/j.healthpol.2005.06.013. 